\title{
On the Current Situation and Future Development Trend of Computer Application in Big Data Age
}

\author{
Suping Sun \\ College of Education, Taiyuan Normal University, Taiyuan, Shanxi, 030619, China \\ sun_suping@126.com
}

Keywords: Big Data, Computer Application, Current Situation, Development Trend.

\begin{abstract}
The development of modern information science and technology is having a strong and sustained deep influence on the development of human society, and the arrival of the big data era has made the computer application technology a qualitative leap. From the point of view of the current situation of computer application, all fields of human life cannot be separated from computer technology, as a tool to improve human productivity, computer technology will develop more applications and progress in the future, and its application field will continue to expand, promote global scientific and technological, economic and social development, play a more important role. This paper expounds the current situation of computer application in the era of big data, and discusses its future development trend..
\end{abstract}

\section{Introduction}

In the process of continuous development and progress of computer science and technology, the arrival of big data era has brought more possibilities for the development of computer technology. As a kind of science and technology that can bring more efficiency and more possibilities to human beings in the future, it will play a great role in promoting the development of human society and economy. With the acceleration of the development of human society, the processing of huge data in various fields of social production and life has become more and more demanding, and the development of computer technology has attracted much attention. In the background of big data era, it is of great significance to study the current situation and trend of computer application technology.

\section{The Development of Computer Applications in the Big Data Age}

The arrival of the big data era has promoted the continuous upgrading of computer applications. Different development directions of computer applications have different advantages and can meet the needs of different fields of work. According to data reported by the International Computer Association, the global total of information processing capacity received per second has exceeded 100 million $\mathrm{T}$, which puts forward higher requirements for the future development level of computer application technology. In the big data era environment, every field of every industry will produce a lot of information materials, thus promoting the transformation of information processing and analysis technology. In the current research of computer application, the security of information technology has become an important research content, people have new demands on the correlation between information and the analysis and application of information and data.

Table 1 The future development trend of big data

\begin{tabular}{|c|c|c|c|}
\hline Year & Year 2018 & 2019 & 2020 \\
\hline Overall market size growth forecast & $39.70 \%$ & $33.30 \%$ & $32.60 \%$ \\
\hline
\end{tabular}

\subsection{Application of Computer Technology in Agriculture}

China has been a big agricultural country since ancient times, and the computer application technology in the big data era has played a very beneficial role in promoting the agricultural 
development of our country. One is that before crops are planted, farmers can widely understand and predict market information through information networks, thus analyzing and predicting which crops are most suitable for planting, and can obtain higher economic benefits. Farmers can also use agricultural technology, weather and climate and other big data to reasonably control the sowing and production process, adjust the arrangement of crop planting area and plant spacing. Second, in the process of crop planting, farmers can use big data information to analyze the amount of pesticide and fertilizer sprayed, scientific and reasonable arrangement of pest and disease control and other work to ensure the healthy growth of crops, reasonable cost control, increase agricultural income, improve the quality of crops. Advanced areas have begun to promote the use of computer technology to achieve automatic control of agricultural irrigation, fertilization and other production activities. Third, after the harvest of crops, farmers can sell crops online, sell crops at a reasonable price, better ensure their own profits, while minimizing the emergence of unsalable crops, improve farmers'economic income. The computer application technology in the era of big data can be combined with the whole process of agricultural production, which provides a lot of reference information for farmers, helps farmers make scientific decisions and raises farmers'income[1].

\subsection{Application of Computer Technology in the Field of Education}

The computer technology in the big data era provides teaching resources and tools for the field of education, so that classroom teaching is no longer bound by time and space, and at the same time, the scientific use of computer technology can greatly improve the quality and effect of teaching. For example, with the rapid development of online courses at the present stage, many colleges and universities and teaching institutions have developed a variety of teaching courses, so that more students can participate in learning through computer technology, which greatly improves the learning efficiency. At the same time, the rich teaching resources have enhanced the students'learning enthusiasm and initiative. Teachers have also used the use of instant messaging tools such as WeChat, further narrowing the distance between teachers and students, teachers and parents, and began to use tools such as WeChat public number and Weibo to spread knowledge and participate in popular science work.

\subsection{Application of Computer Technology in The Field of Public Service}

The computer technology based on the big data era provides more convenience and security for our daily life. Computer technology plays a vital role in business, medical, cultural and other fields. Now, through big data computer technology, we can better grasp the health of the national health, according to different ages, regions, gender, occupation and other information comprehensive analysis, improve the treatment and prevention of national diseases. The application of computer technology in the field of public safety can also maintain social stability and help us to build a society ruled by law better. Public security departments have used a large amount of data information base, can achieve joint investigation, network police use computer application technology to discover network crime, analyze the development trend of network crime, timely find criminals, prevent network crime ahead of time, but also greatly improve the efficiency of catching fugitives. In addition, the use of automated office systems by public security departments can improve working ability and efficiency, improve the quality of information transmission, and give the public better security protection.

Table 2 The overall development level index of big data computer application in various industries

\begin{tabular}{|c|c|c|c|c|c|c|c|c|c|}
\hline Finance & Government & Transportation & Telecommunications & Trade & $\begin{array}{c}\text { Medical } \\
\text { care }\end{array}$ & Education & Tourism & Industry & Agriculture \\
\hline 45.37 & 42.39 & 34.6 & 34.44 & 29.32 & 25.99 & 22.52 & 21.37 & 18.6 & 14.04 \\
\hline
\end{tabular}

\section{The Future Development Trends of Computer Applications in the Big Data Era}

\subsection{To Develop to Intelligence and Automation}

At present, the development of computer technology has greatly improved our work efficiency, 
and its development direction will have the characteristics of automation and intelligence in the future, and gradually realize some human brain and physical labor, and further improve the production efficiency of human society. The computer technology in the big data era can realize the perfect combination with artificial intelligence and better meet the needs of human development. In the near future, technologies and related equipment such as automated laboratories, unmanned workshops and intelligent robots will be widely popularized. With the continuous development of big data and computer application technology, the function of computer is gradually enhanced, and intelligence has become a new development direction. The computer application technology further advances to the artificial intelligence direction, realizes the deeper level human-computer interaction, the computer has the learning, the reasoning and the logical judgment ability. It can imitate people's thinking and make accurate decisions through a lot of information analysis. In the future, the application of artificial intelligence will be more extensive, such as self-driving cars to get mass production greatly improve driving safety, the development of computer technology to intelligence and automation will meet our diverse needs, greatly improve production efficiency and technology level[2].

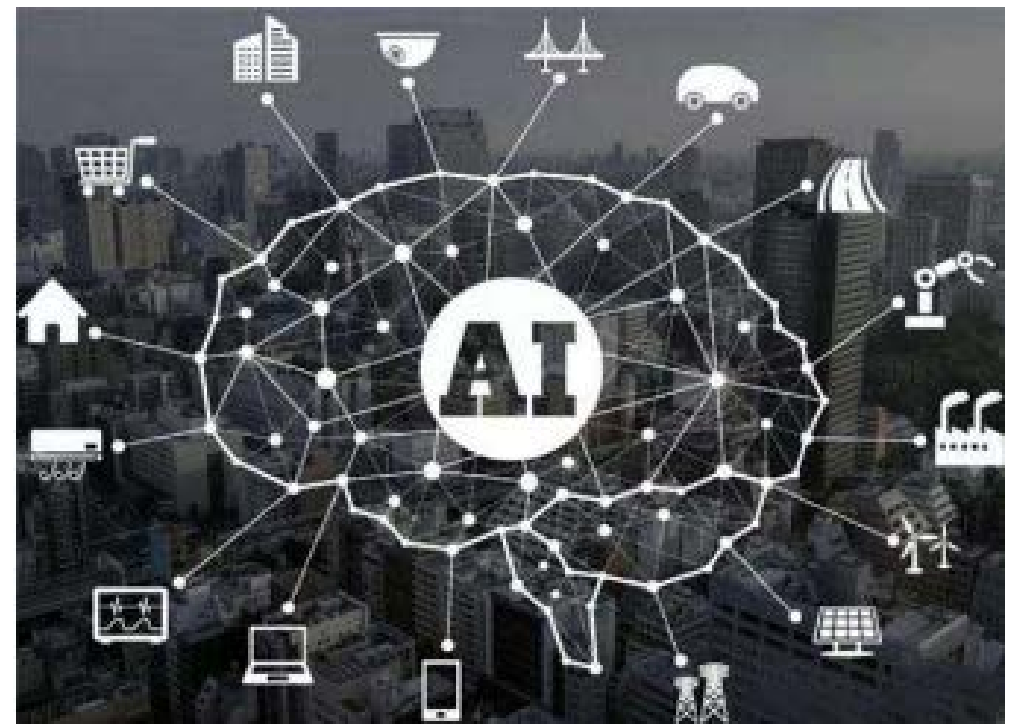

Figure 1 Field map of development and application of artificial intelligence in computer technology

\subsection{Development Towards Miniaturization and Portability}

With the progress of integrated technology, the volume of computer technology equipment is getting smaller and smaller, sports bracelets, mobile phones, laptops and other equipment are gradually moving towards a more portable direction, gradually eliminating the inconvenience caused by the size of the computer and data acquisition equipment, which is conducive to improving the daily work efficiency. The development of big data and Internet of things technology, with the micro-computer parts, so that more electrical equipment and electronic equipment can be linked through computer technology, the future development trend of computer technology will also be closely linked to the development of Internet technology, expand the coverage of network data, more accurate collection, synchronous analysis of data. In the era of big data, the networking of computer technology will further promote the development of communication technology, and provide more convenient and faster service for communication and communication between people. Micro devices and portable devices are linked by Bluetooth technology, network technology,5G and other technologies to form a new and tighter network system, using high-speed information transmission to achieve just a wide range of resource sharing. In the future network system, computer technology will achieve popularization and integrate into all aspects of human production and life. In the future development trend, the application of computer technology will give birth to more high-quality and fully functional computer products[3]。 


\section{Conclusion}

Computer application in the era of big data is an important driving force for the development of science and technology and productive forces in various fields.We should fully recognize the importance of the development of computer application technology, continue to innovate and develop, train high-level talents in the computer industry, raise investment in funds and resources, provide preconditions for the future development of computer technology, and inject vitality into social and economic development. In the environment of big data, the rapid development of computer application technology has promoted the process of information construction in China. With the popularization and application of computer technology, the level of science and technology in various industries has been continuously improved, and the level of service has been continuously improved. Strengthening the research of computer application technology is beneficial to excavate the function and function of computer application technology, accelerate the speed of economic development in our country, and improve the level of economic development.

\section{References}

[1] Cai, Zhiguang. Application of AI Computer Network Technology in Big Data Age. Information Systems Engineering, no. 4, 2019.

[2] Furong, Zhang. Research and Application of Computer Network Technology Development Model in Big Data Era. Digital World, no. 8, 2018.

[3] Li, Changtian. Application Status and Development Prospect of Computer Intelligent Information Processing Technology. Digital World, no. 11, 2018. 